\title{
Update on the Importance of Medical Education in the Changing Field of Pain Medicine
}

\author{
Sabia $\mathrm{M}^{* 1}$, Weaver $\mathrm{M}^{2}$, Gessman $\mathrm{R}^{3}$, and Kalariya $\mathrm{J}^{3}$
}

${ }^{1}$ Division Head Pain Management, Pain Medicine Fellowship Director, Assistant Professor of Anesthesiology, Cooper Medical School of Rowan University, USA

${ }^{2}$ Physical Medicine and Rehabilitation Resident, Cooper Medical School of Rowan University, USA

${ }^{3}$ Anesthesia Resident, Cooper Medical School of Rowan University, Department of Anesthesiology, USA

*Corresponding author: Sabia M, Division Head Pain Management, Pain Medicine Fellowship Director, Assistant Professor of Anesthesiology, Cooper Medical School of Rowan University, Department of Anesthesiology, Division of Pain Management, USA, E-mail: sabia-michael@cooperhealth.edu

Citation: Sabia M, Weaver M, Gessman R, Kalariya J (2017) Update on the Importance of Medical

Education in the Changing Field of Pain Medicine. J Anesth Pati Care 2(1): 103. doi: 10.15744/2456-

5490.2 .103

Received Date: February 15, 2017 Accepted Date: April 07, 2017 Published Date: April 07, 2017

\begin{abstract}
Chronic pain is a pandemic that has spawned the disproportionate opioid epidemic of overuse and over-prescription in the United States. This challenge warrants review of physician education and curriculum to become more effective in pain management. Our current system for educating present and future physicians as well as pain specialists is flawed in a number of ways. The vast majority of physicians will encounter and manage chronic pain patients during their careers, but reviews have demonstrated dissatisfaction among medical students and practitioners with pain education and curriculum. Updating and expanding pain education will improve treatment of chronic pain while limiting over-prescription of opioids. Primary prevention of opioid dependence and abuse is dependent on education and safe opioid prescribing. Changing the educational process and requirements to focus on chronic pain prevention and integrative management to improve functional status and quality of life in those who suffer with chronic pain will require support from several areas: medical educators, clinicians, policymakers, administrators and several other organizations.
\end{abstract}

Keywords: Chronic pain; Curriculum; Medical education; Opioid epidemic; Education; Pain treatment; Teaching; Training programs; Residency Fellowship; Multidisciplinary; Integrated; Multimodal

\section{Introduction}

Pain is one of the leading medical complaints in the United States (U.S.). A country with widespread opioid dependency, a growing population of aging adults with chronic disease, and high demands for pain management specialists [1]. Unfortunately, pain medicine education has not met these demands in quantity nor quality, and ongoing transformation to the curriculum of pain education at the graduate medical level and pre-graduate medical level are both necessary and warranted. This article will review the role of medical education at the medical school and graduate level - including its current status, challenges, and opportunities in the changing field of pain medicine.

\section{Scope of the Problem: Pain as a Disease State}

The American Board of Anesthesiology (ABA) began offering board certification in the field of Pain Medicine in 1993. The specialty has become highly credentialed with one hundred Accreditation Council for Graduate Medical Education (ACGME) accredited fellowship programs either existing in initial or continued accreditation. Yet, pain continues to be a prevalent and costly public health issue for which $\$ 560$ - \$635 billion is spent annually on an estimated 100 million American adults when accounting for health care and lost productivity costs [1]. Perhaps a lesser known fact on the severity of the chronic pain epidemic in the U.S. is that it is more prevalent than diabetes, heart disease, or cancer, estimated at 29.1 million, 85.6 million, and 15.5 million Americans respectively $[2,3,4]$. While traditionally chronic pain was considered a symptom and therefore should not be compared to the aforementioned diseases, chronic pain is now recognized in the literature and the Institute of Medicine to be a unique disease entity with distinct pathology beyond typical classification as a symptom $[1,5]$. Some have even advocated for the creation of a discrete discipline of pain medicine beyond its classification as a subspecialty of neurology, psychiatry, physiatry, or anesthesiology $[6]$. 


\section{The Opioid Epidemic}

With the growing prevalence of chronic pain, it follows that the use of opioids has also increased. However, the number of opioid prescriptions seems to have grown out of proportion to their utility. While 1.5 billion people globally experience chronic pain, Americans are estimated to consume over $80 \%$ of the world's opioids and $99 \%$ of hydrocodone, despite only accounting for $4.6 \%$ of the world's population [7,8]. In fact, between 1999 and 2010, opioid pain medication sales quadrupled to equal enough opioids to be able to administer five milligrams of hydrocodone every four hours to every American for an entire month. Prescription opioid abuse continues to contribute to American mortality and was associated with 33,091 opioid-related overdose deaths in 2015, accounting for an increase by 5,349 deaths (11.4\%) from 2014, continuing a trend observed since 1999 [9].

Confronted with such daunting statistics, American healthcare should place chronic pain at the forefront of its focus. Despite the widespread use of opioids, many patients suffering with chronic pain believe their pain has been inadequately treated in both the outpatient and inpatient setting, and surprisingly even in end of life care. Controlled trials have reported that more than half of all hospitalized patients experienced pain in their final days of life, with 50-75\% of patients dying in moderate to severe states of pain [10]. Such discrepancies can and should be avoided. According to a survey conducted by Peter D. Hart Research Associates for Research American in 2003, seven in ten Americans agree and believe that pain research and management should be one of the medical community's top priorities (16\%) or a high priority (55\%). This survey further revealed that only $15 \%$ of pain sufferers visited a physician who specialized in pain management.

\section{Access to Pain Specialists}

In 2007, a study performed by the American Board of Medical Subspecialties (ABMS) reported only 2,500 physicians were actively certified in pain management [11]. The 2011 Institute of Medicine Report from the Committee on Advancing Pain Research suggests the shortage of certified pain specialists in the U.S. is as severe as only having one certified Pain Medicine specialist for every 28,500 people in need of specialized pain management [5]. Even with the growing need for pain specialists in the U.S. and growing number of physicians and medical schools, the number of certified pain specialists has decreased. As of January 2016 the American Board of Pain Medicine (ABPM) and ABA report only 2,300 certified pain specialists are actively practicing in the U.S. $[12,13]$. Subsequently, the task that lies ahead surrounds the education of future pain specialists to reduce the shortage, manage the most prevalent disease states in the U.S., and modify treatment modalities to address the growing issue of opioid abuse while including evidence-based interdisciplinary approaches.

\section{Training Pain Specialists: Medical Education Challenges}

Initially, ACGME pain fellowship accreditation was subspecialized in the field of anesthesiology and supported by the ABA. Anesthesiology certification and practice requires proficiency at managing perioperative pain, often utilizing interventional procedures and neuraxial techniques for modulation of pain. As pharmaceutical pain management often rested in the hands of primary care providers, pain management subspecialist physicians were only consulted for therapeutic interventions and were not responsible for pharmacologic management. This clinical practice culture, in addition to the fee for service reimbursement model, may have skewed the fellowship educational focus further toward interventional management [14,15]. Unfortunately, this educational model has failed to meet the needs of pain patients and has left pain subspecialists dissatisfied with their pain education [16].

\section{Pain Management in Medical Education Curriculum}

The International Association for the Study of Pain (IASP) originally developed a medical school pain curriculum twenty-five years ago that was updated in 2012, yet education on the topic of pain remains fragmented and inadequate [17]. Pain specialty topics such as geriatric, pediatric, acute, visceral, and cancer pain are generally covered in a limited fashion in medical school or pre-graduate training. Integration of a pain education curriculum would expose undergraduate and graduate medical school students to common concepts in pain medicine to diminish the paucity of pain content and result in greater awareness for all pursuing an education in health sciences [18].

Across 117 U.S. and Canadian medical schools, the average number of hours directed towards pain education was found to be 11.1 hours per program (range: 1 - 31 hours) with American programs trailing its Canadian counterparts, jointly providing only minimal or no coverage of many topics included in the IASP core curriculum [19]. In fact, only $3 \%$ of medical schools in the U.S. directly addressed pain in their curriculum according to a 2008 symposium on pain management [20]. The lack of attention to pain education is not limited to North America, but has also been documented in the UK, Finland, Australia, and New Zealand [21-25].

\section{Pain Medicine as a Primary Medical Specialty}

The deficiency of pain medicine education brings into question the quantity and quality of those charged with the task of teaching effective pain medicine to our newest generations of medical students and establishing an integrated pain medicine curriculum at the level of medical education and graduate medical education. Some see the difficulty in identifying and supporting well- 
trained faculty to teach in medical schools to be a key barrier to successful improvement of medical education in pain medicine [26]. This has been cited as a driving force for ABPM and American Academy of Pain Medicine (AAPM) advocacy for the recognition of "pain medicine as an ABMS recognized primary medical specialty and the development of dedicated ACGMEaccredited residency programs in pain medicine" [27,28]. Other developed countries such as the United Kingdom, Australia, New Zealand and China have already recognized pain medicine as a medical specialty, while the European Union and Canada are also considering this recognition as a means of consolidating interests of multiple specialties and political organizations [26].

\section{A Multidisciplinary Approach to Pain Education: Challenges in Current Training Model}

In the 2007-2008 academic year the ACGME required that accredited pain fellowship programs contain curriculum that includes competencies in neurology, physical medicine and rehabilitation, and psychiatry [29,30]. This requirement follows emphasis from the Institute of Medicine on the need for interprofessional education (IPE) and collaborative practice. There has been a trend toward implementation of IPE programs to allow two or more professions to learn with, from, and about each other in an effort to empower the development of health care providers who are comfortable working in collaboration to promote quality of care [31-33]. These curriculum requirements for "multidisciplinary pain fellowships" have been defined by the IASP Core Curriculum for Professional Education in Pain with the goal of limiting variability in postgraduate training exposure.

In clinical practice, typical multidisciplinary treatment for pain includes elements of medication management, graded physical exercise, cognitive and behavioral therapy, and management of stress and environmental factors [34,35]. While often used interchangeably, the term interdisciplinary describes pain management that is multidisciplinary and is also coordinated at the same facility with face-to-face daily communication and collaborative decision-making [36,37]. The terminology can be cumbersome, but generally, in order of increasing comprehensiveness and collaboration a summary of the evolving terms for patient care models include: unimodal, parallel, collaborative, coordinated, multidisciplinary, interdisciplinary, and integrative approaches [38]. It is this premise of integration for which we as a specialty must strive. This integration beyond physician specialties includes co-training of other members of the health care team that regularly manage chronic pain such as nursing staff, physiotherapists, occupational therapists, and social workers. Each member of the pain management team plays a role in understanding, interpreting, and effectively managing a patient's experience with pain in an effort to regain quality adjusted life years (QALY).

While the ACGME still requires competency in numerous injections and nerve blocks, the focus has shifted towards a multidisciplinary model to incorporate knowledge of the biomechanics and biopsychosocial aspects of pain. Additionally, the ACGME has recommended increasing experience with cancer patients and palliative care patients. Unfortunately, some fellowship programs have found difficulty adapting to the changing direction of pain education in the U.S. In fact, within the past 10 years, sixteen multidisciplinary pain management fellowship programs have withdrawn from ACGME accreditation. Unfortunately, the reason for withdrawal of these programs remains unclear and warrants further investigation including a root cause analysis. Perhaps this is in part due to the limitations in clinical exposure variability due to geographic location and patient population size and density. Further, the majority of accredited pain medicine subspecialists have anesthesiology backgrounds because most fellowship programs remain associated with Anesthesiology Departments. This may continue selection bias towards anesthesiology residency graduates and limit graduates of neurology, psychiatry, or physiatry into the work pool of pain medicine specialists [39].

\section{The Need for Integrated Graduate Medical Education in Pain}

Despite the ACGME attempt to transition pain fellowship programs to a multidisciplinary approach to include education in neurology, psychiatry, and physiatry, few fellowships offer longitudinal integration of these perspectives in clinical practice and patient care. While fellowship requirements now guarantee exposure to perspectives of different medical subspecialties in their approach to pain care during month-long blocks there is no guarantee that this exposure will be in the context of an interdisciplinary team. Thus, it is still possible the ACGME requirement changes will improve awareness of pain treatment approaches but will leave fellows graduating without the knowledge to incorporate these approaches in an interdisciplinary clinical practice. Further, many complementary and alternative medicine modalities, including yoga, acupuncture, physical therapy, meditation, and cognitive behavioral therapy that have garnered support in the literature in their effectiveness for holistic chronic pain management remain excluded from ACGME core requirements for pain fellowships. Unfortunately so, as many of these modalities are directed more towards primary prevention of pain through reduction in pain inducers such as body mass index, stress, access, etc., and may be more effective in eliminating the root cause of the rising chronic pain prevalence than many of the secondary and tertiary interventions that comprise the focus of current training.

With the new ACGME requirements and less time to obtain sufficient interventional procedural exposure to effectively practice following fellowship graduation, the ABA has proposed that pain fellowships should be extended to a two year post residency training model. However, this must be considered in the context of significant financial debt incurred in undergraduate and medical education tuition and lost wages during residency training $[26,40]$.

\section{Lack of Effective National and State Pain Policy}

Despite the interdisciplinary pain management movement originating in the United States, interdisciplinary clinical practices have been declining dramatically in contrast to increases in other industrialized countries with National Health Services [41]. This 
may be attributable to the lag in payment model reform to reimburse interdisciplinary clinical practice algorithms beyond the fee for service model [15]. In contrast to other nations that have implemented interdisciplinary pain management practices, the U.S. lacks a consistent national pain policy. Without a national pain policy, interdisciplinary pain practices have met challenges offering evidence-based complementary and alternative medicine techniques due to poor reimbursement or lack of coverage under their health insurance plans [41,42]. While the US Affordable Care Act (ACA) promoted research and treatment for pain care management, it lacked provisions for improving access to interdisciplinary chronic pain management for the vast majority of Americans [43]. It has been suggested that the cost effectiveness of interdisciplinary pain management could potentially save billions of dollars per year for the American health care system that is already facing financial instability. Organizations such as State Pain Policy Advocacy Network (SPPAN) continue to promote access to interdisciplinary pain care at the state and federal level [44]. In spite of resistance from third-party payers to implement coverage with increased short-term expenses, cost effectiveness of interdisciplinary pain management is projected to save billions of dollars per year and return millions of Americans to functional restoration and higher quality of life [45].

\section{Conclusion and Future Perspective}

The future of American health care and our approach to pain management is adapting, albeit slowly, to the growing needs of our nation. Given the severity of the chronic pain pandemic and the demands for pain management specialists, medical and graduate medical pain education is poised for an overhaul. National pain policy creation and implementation is crucial to address this disease burden. It remains uncertain how the field of pain medicine will evolve to meet the needs of our patients, whether it will become a discrete discipline, a distinct residency, or simply grow to a 2-year fellowship within the subspecialty of anesthesiology. However, it is clear that subspecialty training should be restructured not only in an interdisciplinary manner but also in which practitioners work together as a cohesive team for the most valuable and efficient exchange of ideas and treatment modalities. Regardless of the way in which the need is met, the future goal of pain subspecialty training should focus on how we can best improve the health and functional outcomes of our patients.

\section{References}

1. Institute of Medicine Report from the Committee on Advancing Pain Research, Care, and Education (2011) Relieving Pain in America: A Blueprint for Transforming Prevention, Care, Education, and Research. Washington, DC. The National Academies Press 2011.

2. American Diabetes Association (2016) Statistics about Diabetes. Last Edited 12/12/16. Accessed on Dec 15, 2016.

3. Mozaffarian D, Benjamin EJ, Go AS, Arnett DK, Blaha MJ, et al. (2016) Heart Disease and stroke statistics-2016 update: a report from the American Heart Association 133: e38-360.

4. American Cancer Society (2016) Cancer Treatment \& Survivorship Facts \& Figures 2016-2017. Atlanta: American Cancer Society.

5. Siddall PJ, Cousins MJ (2004) Persistent pain as a disease entity: implications for clinical management. Anesth Analg 99: 510-20.

6. Fishman SM, Gallagher RM, Carr DB, Sullivan LW (2004) The case for pain medicine. Pain Med 5: 281-6.

7. Global Industry Analysts, Inc. Report. Accessed on January 10, 2011.

8. Manchikanti L (2007) National drug control policy and prescription drug abuse: facts and fallacies. Pain Physician 10: $399-424$.

9. Rudd RA, Seth P, David F, Scholl L (2016) Increases in Drug and Opioid-Involved Overdose Deaths-United States, 2010-2015. MMWR Morb Mortal Wkly Rep 65: 1445-52.

10. Alfred F. Connors Jr, Neal V. Dawson, Norman A. Desbiens, et al. (1995) Controlled Trial to Improve Care for Seriously Ill Hospitalized Patients. JAMA 274: 1591-8.

11. Breuer B, Pappagallo M, Tai JY, Portenoy RK (2007) US board-certified pain physician practices: uniformity and census data of their locations. J Pain 8: 244-50. 12. American Board of Pain Medicine. "FAQs". Accessed December 2016.

13. American Board of Anesthesiology (ABA) (2016) News 2016 Collaboration. Accessed in January 2017.

14. Caudill-Slosberg, Margaret A, Schwartz, Lisa M, Woloshin, Steven (2004) Office visits and analgesic prescriptions for musculoskeletal pain in US: 1980 vs. 2000. Pain 109: 514-9.

15. James P Rathmell, David Brown (2008) Education, Training, and Certification in Pain Medicine. Practical Management of Pain 7: 78-83

16. Vadivelu N, Mitra S, Hines R, Elia M, Rosenquist RW (2012) Acute pain in the undergraduate medical education: an unfinished chapter! Pain Pract 12: 663-71.

17. International association for the study of pain (IASP) (2014) IASP interprofessional pain curriculum outline.

18. Doorenbos AZ, Gordon DB, Tauben D, Palisoc J, Drangsholt M, et al. (2013) A Blueprint of Pain Curriculum across Prelicensure Health Sciences Programs: One NIH Pain Consortium Center of Excellence in Pain Education (CoEPE) Experience. J Pain 14: 1533-8.

19. Mezei L, Murinson BB, Johns Hopkins Pain Curriculum Development Team (2011) Pain education in North America medical schools. J Pain 12: 1199-1208.

20. Symposium on Pain Management Aimed at Medical School Students (2008).

21. Kress HG (2013) The importance of putting pain on the curricula in mediacl schools in Europe. J Pain Palliat Care Pharmacother 27: 182-4.

22. Briggs E. Whittaker M, Carr E (2009) Pain Education Special Interest Group of the British Pain Society. Survey of Undergraduate Pain Curricula for Healthcare Professionals in the UK. The British Pain Society, London, UK (2009).

23. Poyhia R, Kalso E (1999) Pain related undergraduate teaching in medical faculties in Finland. Pain 79: 121-5.

24. Watt-Watson J, McGillion M, Hunter J, Choiniere M, Clark AJ, et al. (2009) A survey of pre-licensure pain curricula in health science faculties in Canadian Universities. Pain Res Manag 14: 439-44.

25. MacIntyre PE, Scott DA, Schug SA, Visser EJ, Walker SM (2010) Working Group of the Australian and New Zealand College of the Anaesthetists and Faculty of Pain Medicine, Acute pain management: Scientific evidence ( $3^{\text {rd }}$ Edition). (Eds) ANZCA \& FPM, Melbourne, Australia. 
26. Gallagher RM (2002) Pain education and training: Progress or paralysis? Pain Med 3: 196-7.

27. Dubois MY, Gallagher RM, Lippe PM (2009) Pain medicine position paper. Pain Med 10: 972-1000.

28. American Board of Pain Medicine (ABPM) Talking points: Why the US Should Develop a Primary Medical Specialty in Pain Medicine. Accessed on December $12,2016$.

29. Accreditation Council for Graduate Medical Education (ACGME) (2016) ACGME Program Requirements for Graduate Medical Education in Pain Medicine (Anesthesiology, Neurology, or Physical Medicine and Rehabilitation). Last Revised July 1, 2016.

30. Benzon HT, Rathmell JP, Huntoon MA (2007) New ACGME requirements for fellowship training in pain medicine. Am Pain Soc Bull 17: 5-7.

31. Institute of Medicine. Health professions education: a bridge to quality. Washington DC, National Academy Press, 2003.

32. World Health Organization (2010) Framework for action on interprofessional education and collaborative practice, USA.

33. Centre for the Advancement of Interprofessional Education (2016) Defining IPE, UK.

34. Block A, Kremer EF, Fernandez E (1999) Clinical outcome and economic evaluation of multidisciplinary pain centers. In: Handbook of Pain Syndromes: Biopsychosocial Perspectives, Mahwah, NJ: Lawrence Erlbaum Associates, USA.

35. National Pain Summit Initiative. National pain strategy: pain management for all Australians. Melbourne: Faculty of Pain Medicine; 2010, Australia.

36. Turk DC, Paice JA, Cowan P, Stanos SP, Jamison RN, et al. (2009) Interdisciplinary Pain Management: Task Force Report developed for American Pain Society, USA.

37. Gatchel RJ, McGeary DD, McGeary CA, Lippe B (2014) Interdisciplinary chronic pain management: Past, present, and future. American Psychologist 69: $119-30$.

38. Stanos S, Houle TT (2006) Multidisciplinary and interdisciplinary management of chronic pain. Phys Med Rehabil Clin N Am 17: 435-50.

39. Brotherton SE, Etzel SI (2007) Graduate medical education, 2006-2007. JAMA 298: 1081-96.

40. Lema MJ (2002) What's the name of the game? ASA Newsletter 66.

41. Schatman ME (2012) Interdisciplinary chronic pain management: international perspectives. Pain: Clin Updates 20: 1-5.

42. Jeffery MM, Butler M, Stark A, Kane RL (2011) Multidisciplinary pain programs for chronic noncancer pain. Rockville, MD: Agency for Healthcare Research and Quality, USA.

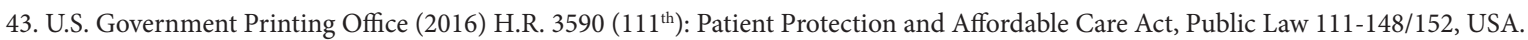

44. American Academy of Pain Management: State pain policy network, USA.

45. Schatman ME (2010) Interdisciplinary chronic pain management: perspectives on history, current status, and future viability In: Bonica’s management of pain (4 ${ }^{\text {th }}$ Edn) Philadelphia: Lippincott, Williams \& Wilkins, USA.

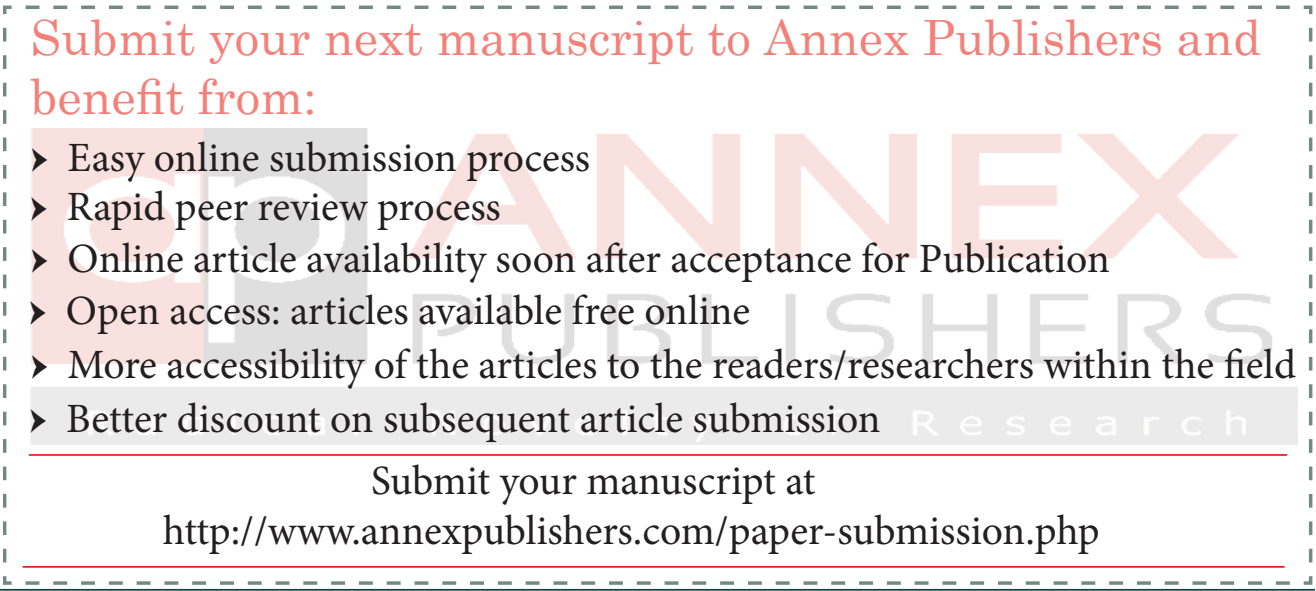

